\title{
Race and education in relation to stopping smoking in the US: the CARDIA Study
}

\author{
Lynne E Wagenknecht, Teri A Manolio, Cora E Lewis, Laura L Perkins, \\ Harry A Lando, Stephen B Hulley
}

Bowman Gray School of Medicine,

Department of Public Health Sciences, Winston-Salem, NC 27157-1063, USA

L E Wagenknecht

National Heart, Lung, and Blood Institute, Division of

Epidemiology and Clinical Applications, Bethesda, MD 20892,

USA

T A Manolio

University of

Alabama at

Birmingham, School

of Medicine,

Department of

General and

Preventive Medicine,

Birmingham, AL

35294, USA

C E Lewis

University of

Alabama at

Birmingham, School

of Public Health,

Department of

Biostatistics,

Birmingham, AL

35294, USA

L L Perkins

University of

Minnesota, Division of

Epidemiology, School

of Public Health,

Minneapolis, MN

55454 , USA

$\mathrm{H}$ A Lando

University of

California at San

Francisco,

Department of

Epidemiology and

Biostatistics,

San Francisco, CA

94143, USA

$S$ B Hulley

Correspondence to: $\mathrm{D}$

Lynne Wagenknecht,

Bowman Gray School of

Medicine, Department of

Public Health Sciences,

Medical Center Blyd,

Winston-Salem, NC 27157

1063, USA

\begin{abstract}
Objective-To assess possible explanations for lower smoking cessation rates among black Americans and among those who are less well educated.
\end{abstract}

Design - Data from three years of followup in CARDIA, a multicentre, longitudinal study of the evolution of cardiovascular disease risk factors.

Subjects - Urban adults aged 20-32 years, with roughly equal numbers of men and women and of blacks and whites.

Main outcome measures - Rates and predictors of attempts to stop smoking and success at stopping smoking.

Results-More than one-half (645/1131) of the subjects who reported smoking in $1987 / 88$ attempted to stop in the succeeding three years; one in five was successful. White smokers were more likely to attempt to stop smoking (univariate odds ratio $(O R)=1.31$ ) and were more successful in their attempts than blacks $(O R=1.80)$. Similarly, better educated subjects were more likely to attempt to stop smoking and to succeed. In a logistic regression model, adjusting for demographic and smoking characteristics, association with other smokers, and the type of cessation method, white race persisted as an independent predictor of success, but not of attempt. Better education was not an independent predictor of attempt or success in the overall sample. Other predictors of attempt included a higher annual income and a shorter smoking history. Those who succeeded smoked fewer cigarettes per day and were less likely to be exposed to smoke in the home.

Conclusions - Although a number of predictors of smoking cessation were identified, none explained the lower success of blacks than whites. There is a need for understanding the causes and implementing strategies if this disparity is to be overcome.

(Tobacco Control 1993; 2: 286-92)

\section{Introduction}

Smoking cessation is an important element in the control of tobacco use today. The benefits of smoking cessation are profound; after 10-15 years of abstinence, the risk of all-cause mortality returns to that of a never smoker. ${ }^{1}$ Regardless, many smokers never attempt to stop smoking and others find continued abstinence difficult. These conditions differ across subgroups. For example, smoking cessation rates are lower in black American adults than in whites ${ }^{2,3}$ and in less well educated individuals compared to the more educated..$^{2,4}$ A better understanding of the underlying reasons for these disparities may provide additional ammunition for interventions aimed at controlling tobacco use.

Numerous investigators have sought to identify the predictors of smoking cessation, ${ }^{5-14}$ yet none have specifically examined the predictors among black Americans nor among the less well educated. One survey has characterized black life insurance policyholders who were current smokers and ex-smokers. ${ }^{11}$ The potential for recall bias and the poor generalisability of the sample are areas for improvement in future studies.

The present report examines data collected as part of an ongoing study of cardiovascular disease risk factors in young adults. Smoking data have been collected prospectively in a large, general sample of black and white Americans of varied educational backgrounds. The goals of the report are to focus on race and educational differences in smoking cessation with regard to attempts to stop smoking and success rates, predictors of attempt and success, and methods and motivations associated with attempts.

\section{Methods}

The CARDIA (Coronary Artery Risk Development In young Adults) study is a longitudinal, epidemiologic study of the evolution of cardiovascular disease risk factors in an urban sample of 5115 young adults. The study design and smoking behaviour of the cohort have been described previously. ${ }^{2,15}$ Subjects were recruited such as to balance several demographic characteristics within the cohort: race (black, white), sex, age (18-24, 25-30 years), and education (high school or less, more than high school). Initially examined in $1985 / 86$, follow-up examinations of the cohort were conducted in 1987/88 and 1990/91. Although the prevalence of smoking among black subjects paralleled that of all black young 
Table 1 Classification of CARDIA participants with respect to their attempts to stop smoking between the 1987/88 and 1990/91 examinations

Self-reported smoking status

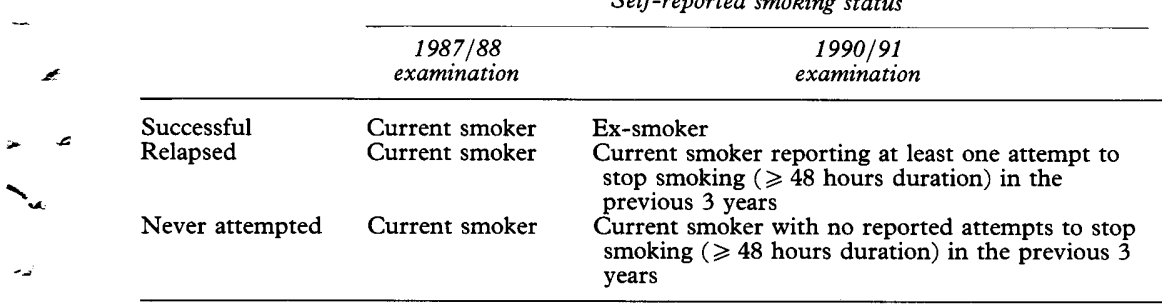

$<$ adults who were approached about the study, white smokers were under-represented in the study. ${ }^{2}$ As anticipated, follow-up rates were lower in smokers than non-smokers in all racial groups: for the $1987 / 88$ and $1990 / 91$ followup examinations, respectively, rates were $87 \%$ and $81 \%$ among smokers, compared to $92 \%$ and $87 \%$ among non-smokers.

Data for this report were obtained from all CARDIA subjects who reported smoking in $1987 / 88$ and who also attended the 1990/91 examination three years later. A smoker was defined by self-report of regular smoking, ie, five cigarettes per week for at least three months. Those who reported, at the 1990/91 examination, "any attempt to stop smoking cigarettes" in the previous three years, were questioned further regarding the duration of the attempt(s) and methods and motivations leading to their attempt(s) to stop. Subjects are hereafter classified according to their smoking status reported on the day of their 1990/91 examination (table 1). An attempt was defined as any attempt to stop smoking, of at least 48 in 1990/91 never having smoked. in 1990/91 never having smoked. 1990/91 examinations hours' duration, in the previous three-year period. Those who described themselves as exsmokers on the day of their 1990/91 examination were classified as successful quitters. The period of continuous abstinence is not known.

Logistic regression was conducted to determine predictors of attempt and success. All two-way interactions with race and with education were tested. In the model examining predictors of attempt, those who were successful and those who relapsed are combined and compared to those who did not attempt to stop. Multiple race interactions were observed $(\mathrm{p}<0.20$; see table 4 footnote for details); consequently, models are presented overall and by race. In the model examining success, those who were successful were compared to those who attempted to stop but relapsed. Multiple education interactions were observed, but no race interactions were observed. These data are presented by education category.

Variables which were examined as potential predictors of attempt and success were obtained from data collected in 1987/88 and $1990 / 91$. Variables collected in 1987/88 included age, education, the average number of cigarettes smoked per day, the number of years smoked regularly, the number of hours/week of exposure to smoke in the home, and an indication of whether most of the participant's friends were smokers. Variables from the 1990/91 examination include annual family income, the time of the day the first cigarette is smoked, and the portion of the cigarette that is smoked. Among former smokers, the latter were asked in reference to the last time the

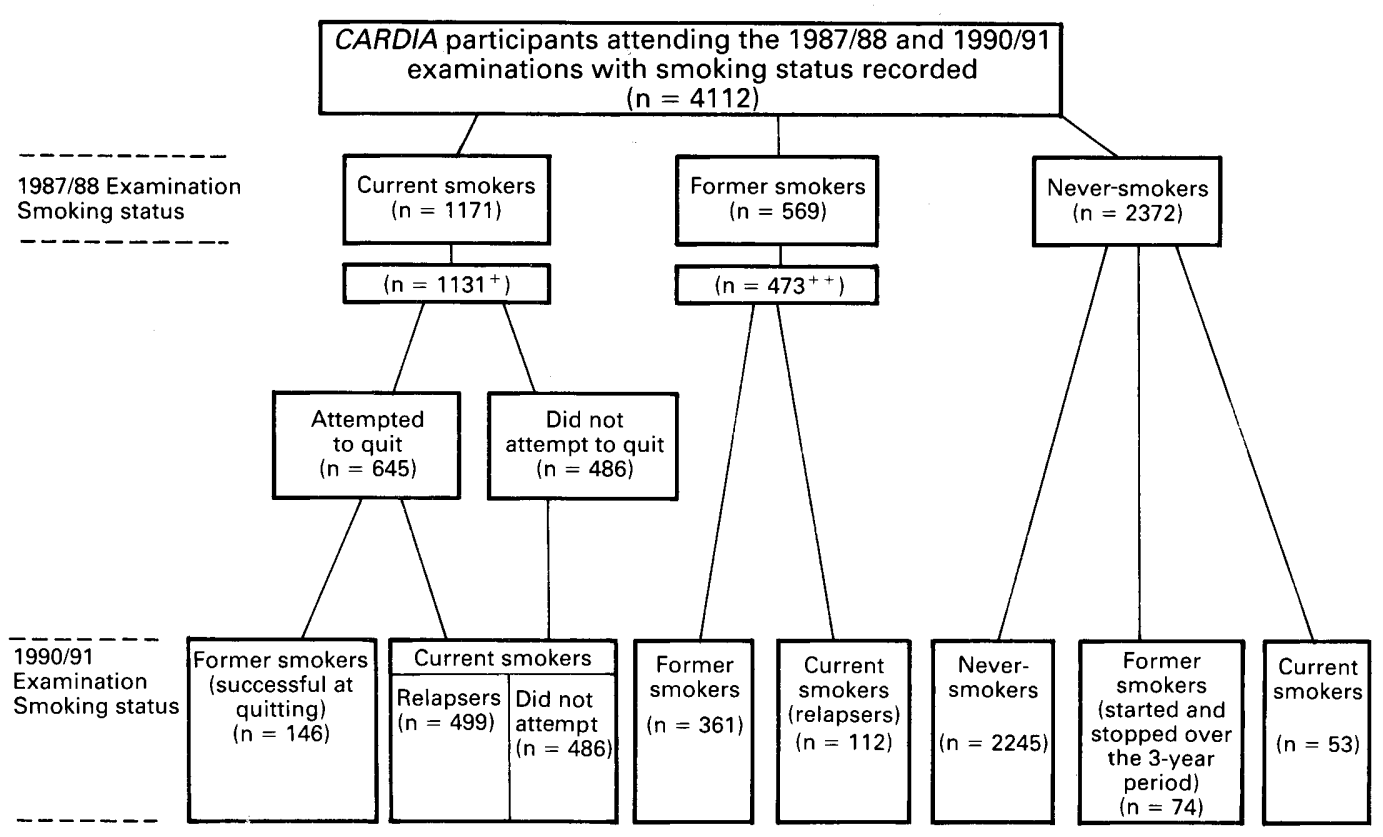

${ }^{+}$Misreports $(n=40)$ have been excluded, ie, current smokers in $1987 / 88$ who reported

${ }^{++}$Misreports $(n=96$ ) have been excluded, ie, former smokers in $1987 / 88$ who reported

Figure 1 Smoking status and attempts to quit smoking: CARDIA subjects attending both the $1987 / 88$ and 
Table 2 Characteristics of all CARDIA smokers and of those who were successful, those who relapsed, and those who never attempted to stop smoking between the $1987 / 88$ and $1990 / 91$ examinations, by race

\begin{tabular}{|c|c|c|c|c|c|c|c|c|c|}
\hline & \multicolumn{3}{|c|}{ All smokers } & \multicolumn{3}{|c|}{ Black } & \multicolumn{3}{|c|}{ White } \\
\hline & $\begin{array}{c}A l l \\
(n=1131)\end{array}$ & $\begin{array}{c}\text { Black } \\
(n=632)\end{array}$ & $\begin{array}{c}\text { White } \\
(n=499)\end{array}$ & $\begin{array}{c}\text { Successful } \\
(n=61)\end{array}$ & $\begin{array}{l}\text { Relapsed } \\
(n=281)\end{array}$ & $\begin{array}{c}\text { Never } \\
\text { attempted } \\
(n=290)\end{array}$ & $\begin{array}{c}\text { Successful } \\
(n=85)\end{array}$ & $\begin{array}{l}\text { Relapsed } \\
(n=218)\end{array}$ & $\begin{array}{c}\text { Never } \\
\text { attempted } \\
(n=196)\end{array}$ \\
\hline Sex ( $\%$ female $)$ & 52 & 53 & 51 & 56 & 57 & 49 & 62 & 49 & 48 \\
\hline Age (years) & $\begin{array}{l}27.5 \\
(3.6)\end{array}$ & $\begin{array}{l}27.4 \\
(3.7)\end{array}$ & $\begin{array}{l}27.7 \\
(3.4)\end{array}$ & $\begin{array}{l}28.0 \\
(3.2)\end{array}$ & $\begin{array}{l}27.2 \\
(3.8)\end{array}$ & $\begin{array}{l}27.3 \\
(3.8)\end{array}$ & $\begin{array}{l}27.4 \\
(3.5)\end{array}$ & $\begin{array}{l}27.7 \\
(3.3)\end{array}$ & $\begin{array}{l}27.8 \\
(3.5)\end{array}$ \\
\hline $\begin{array}{l}\text { Age when began smoking } \\
(\% \leqslant 15 \text { years old })\end{array}$ & 33 & 30 & $38^{a}$ & 28 & 30 & 31 & 27 & 35 & $44^{b}$ \\
\hline Education (years) & $\begin{array}{l}13.0 \\
(2.1)\end{array}$ & $\begin{array}{l}12.6 \\
(1.8)\end{array}$ & $\begin{array}{l}13.6^{a} \\
(2.3)\end{array}$ & $\begin{array}{l}13.0 \\
(2.0)\end{array}$ & $\begin{array}{l}12.7 \\
(1.7)\end{array}$ & $\begin{array}{l}12.4^{b} \\
(1.8)\end{array}$ & $\begin{array}{l}14.6 \\
(2.4)\end{array}$ & $\begin{array}{l}13.8 \\
(2.2)\end{array}$ & $\begin{array}{l}13.0^{b} \\
(2.4)\end{array}$ \\
\hline $\begin{array}{l}\text { Annual family income } \\
(\% \geqslant \$ 25000)\end{array}$ & 49 & 36 & $65^{a}$ & 44 & 40 & $30^{b}$ & 74 & 72 & $55^{b}$ \\
\hline Years smoked regularly & $\begin{array}{c}9.4 \\
(4.7)\end{array}$ & $\begin{array}{c}8.9 \\
(4.7)\end{array}$ & $\begin{array}{r}9.9^{a} \\
(4.7)\end{array}$ & $\begin{array}{c}7.2 \\
(3.8)\end{array}$ & $\begin{array}{l}8.7 \\
(4.5)\end{array}$ & $\begin{array}{r}9.6^{b} \\
(5.0)\end{array}$ & $\begin{array}{c}8.4 \\
(4.8)\end{array}$ & $\begin{array}{c}9.9 \\
(4.5)\end{array}$ & $\begin{array}{l}10.5^{b} \\
(4.8)\end{array}$ \\
\hline $\begin{array}{l}\text { Cigarettes smoked } \\
\text { per day }\end{array}$ & $\begin{array}{l}13.6 \\
(9.6)\end{array}$ & $\begin{array}{l}11.4 \\
(8.0)\end{array}$ & $\begin{array}{l}16.5^{a} \\
(10.6)\end{array}$ & $\begin{array}{c}8.3 \\
(5.5)\end{array}$ & $\begin{array}{l}11.1 \\
(7.6)\end{array}$ & $\begin{array}{l}12.3^{b} \\
(8.7)\end{array}$ & $\begin{array}{l}11.7 \\
(10.1)\end{array}$ & $\begin{array}{l}16.7 \\
(9.9)\end{array}$ & $\begin{array}{l}18.3^{b} \\
(10.9)\end{array}$ \\
\hline $\begin{array}{l}\text { Hours/week exposed } \\
\text { to smoke in home }\end{array}$ & $\begin{array}{c}22.5 \\
(25.8)\end{array}$ & $\begin{array}{c}23.3 \\
(25.9)\end{array}$ & $\begin{array}{l}21.6 \\
(25.7)\end{array}$ & $\begin{array}{l}17.1 \\
(22.5)\end{array}$ & $\begin{array}{c}23.6 \\
(27.0)\end{array}$ & $\begin{array}{l}24.3 \\
(25.4)\end{array}$ & $\begin{array}{l}12.4 \\
(19.1)\end{array}$ & $\begin{array}{l}21.2 \\
(26.0)\end{array}$ & $\begin{array}{r}26.0^{b} \\
(26.9)\end{array}$ \\
\hline $\begin{array}{l}\text { Most of your friends } \\
\text { are smokers }(\%)\end{array}$ & 59 & 65 & $51^{a}$ & 51 & 62 & $71^{b}$ & 41 & 50 & $57^{b}$ \\
\hline $\begin{array}{l}\text { First cigarette within } \\
30 \text { min of waking }(\%)\end{array}$ & 48 & 52 & $43^{a}$ & 40 & 45 & $61^{b}$ & 27 & 43 & $50^{b}$ \\
\hline $\begin{array}{l}\text { Smokes nearly all of } \\
\text { the cigarette }(\%)\end{array}$ & 20 & 21 & 19 & 34 & 15 & 23 & 29 & 21 & $13^{b}$ \\
\hline
\end{tabular}

Note: Mean and standard deviation are presented for continuous variables, percentages for binary variables. "Smokes nearly all of the cigarette", corresponds to the phrasing of the questionnaire: "very little" of the cigarette burns without smoking it; other responses were "some", "moderate amount", and "a great
deal". Variables collected in 1987/88 included age, education, years smoked regularly, cigarettes smoked per day, hours/week exposed to smoke in home and most of your friends are smokers. Variables collected in 1990/91 included income, time of the day the first cigarette is smoked, and the portion of the cigarette that is smoked (see text for additional information).

${ }^{a}$ Significant race difference between black and white $(p<0.05)$

${ }^{b}$ Significant trend using either the chi-square test for trend in binomial proportions or a test for linear trend $(p<0.05)$.

person smoked. (These latter variables are not true predictor variables and should be viewed with caution.)

Subjects who reported at least one attempt to stop smoking were asked whether they had tried any of the following methods: stopping or trying to stop cold turkey, cutting down or switching brands, going to a doctor or professional agency, or any other method. These methods, including the "other" category, were later classified as unassisted or assisted according to a previously described scheme. ${ }^{10}$ Assisted methods included attending a smoking cessation programme, consulting a doctor or professional agency, obtaining hypnosis or acupuncture, or using nicotine gum or a nicotine skin patch. All other methods were considered unassisted.

Table 3 Smoking cessation attempt rates and success rates in a three-year period in CARDIA smokers by race, education and sex : 1987/88-1990/91

\begin{tabular}{|c|c|c|c|c|c|c|}
\hline & \multicolumn{3}{|c|}{$\begin{array}{l}\text { Attempt rates among } \\
\text { all smokers }\end{array}$} & \multicolumn{3}{|c|}{$\begin{array}{l}\text { Success rates among } \\
\text { those who attempted }\end{array}$} \\
\hline & $n$ & $\%$ & $\begin{array}{c}\text { Crude OR } \\
(95 \% C L)\end{array}$ & $n$ & $\%$ & $\begin{array}{c}\text { Crude OR } \\
(95 \% C L)\end{array}$ \\
\hline $\begin{array}{l}\text { Race } \\
\text { White } \\
\text { Black }\end{array}$ & $\begin{array}{l}499 \\
632\end{array}$ & $\begin{array}{l}61 \\
54\end{array}$ & $\begin{array}{c}1.31 \\
(1.03,1.66)\end{array}$ & $\begin{array}{l}303 \\
342\end{array}$ & $\begin{array}{l}28 \\
18\end{array}$ & $\begin{array}{c}1.80 \\
(1.24,2.61)\end{array}$ \\
\hline $\begin{array}{l}\text { Education } \\
\quad \geqslant 12 \text { years } \\
\leqslant 12 \text { years }\end{array}$ & $\begin{array}{l}509 \\
621\end{array}$ & $\begin{array}{l}64 \\
51\end{array}$ & $\begin{array}{c}1.72 \\
(1.36,2.19)\end{array}$ & $\begin{array}{l}327 \\
317\end{array}$ & $\begin{array}{l}27 \\
19\end{array}$ & $\begin{array}{c}1.59 \\
(1.09,2.31)\end{array}$ \\
\hline $\begin{array}{l}\text { Sex } \\
\text { Female } \\
\text { Male }\end{array}$ & $\begin{array}{l}590 \\
541\end{array}$ & $\begin{array}{l}60 \\
54\end{array}$ & $\begin{array}{c}1.29 \\
(1.02,1.63)\end{array}$ & $\begin{array}{l}354 \\
291\end{array}$ & $\begin{array}{l}25 \\
20\end{array}$ & $\begin{array}{c}1.28 \\
(0.88,1.86)\end{array}$ \\
\hline Overall & 1131 & 57 & - & 645 & 23 & - \\
\hline
\end{tabular}

Note : Definitions of attempt rate and success rate are presented in the text. Sample size is reduced by one in the education comparison due to missing education data. $\mathrm{CL}=$ confidence limits.

\section{Results}

Among the 4112 subjects who attended both the $1987 / 88$ and $1990 / 91$ examinations and for whom smoking data were recorded, the smoking prevalence rate did not change. Twentyeight percent $(1171 / 4112)$ of the subjects were reported smokers at the $1987 / 88$ examination (figure 1). In the following three-year period, 146 subjects stopped smoking while 165 began (53 for the first time and 112 relapsed) for a smoking prevalence rate of $28 \%$ at the $1990 / 91$ examination. This report focuses on 1131 of the 1171 subjects who were reported smokers at the $1987 / 88$ examination. (Forty of the 1171 subjects were excluded for inconsistent data regarding smoking status.)

\section{DESCRIPTIVE STATISTICS}

The mean age of the sample in $1987 / 88$ was 28 years, and the mean education was 13 years (table 2). Fifty-six percent $(632 / 1131)$ of the sample was black. Black smokers were less well educated, reported lower family incomes, and were more likely to have friends who were smokers. On average, blacks reported starting smoking at an older age, smoking for fewer years, and smoking fewer cigarettes per day than whites. Blacks more often reported smoking their first cigarette within 30 minutes of waking. The use of "other" tobacco products in this sample was minimal; at the 1990/91 examination there were 10 cigar smokers, one pipe smoker and four users of chewing tobacco.

\section{ATTEMPT AND SUCCESS RATES}

Fifty-seven percent $(645 / 1131)$ of the smokers attempted to stop smoking at least once during 
the three-year period (table 3 and figure 1). The attempt rate was higher in whites than blacks $(\mathrm{OR}=1.31)$, higher among the better educated than the less well educated $(\mathrm{OR}=$ 1.72), and higher in women than men ( $O R=$ 1.29). Of those who attempted to stop, $23 \%$ were successful, resulting in a 3-year quit rate among all smokers of $13 \%(146 / 1131)$. The success rate was higher in whites than blacks $(\mathrm{OR}=1.80)$ and higher among the better educated $(\mathrm{OR}=1.59)$.

Table 4 Adjusted odds ratios (95\% confidence limits) for various predictors of attempt to stop smoking by race

\begin{tabular}{lccc}
\hline & Black & White & All \\
\hline$(\mathrm{n} / \mathrm{n})^{a}$ & $(326 / 274)$ & $(296 / 193)$ & $(622 / 467)$ \\
Race & & & 1.14 \\
white (vs black) & - & - & $(0.86,1.51)$ \\
Education & 0.96 & 1.93 & 1.30 \\
$\geqslant 12$ yrs (vs <12) & $(0.67,1.39)$ & $(1.28,2.89)$ & $(1.00,1.70)$ \\
Sex & 1.35 & 1.24 & 1.23 \\
female (vs male) & $(0.96,1.90)$ & $(0.83,1.85)$ & $(0.95,1.58)$ \\
Annual family income & 1.52 & 1.94 & 1.68 \\
$\geqslant \$ 25000$ (vs $<25000)$ & $(1.06,2.20)$ & $(1.28,2.94)$ & $(1.28,2.21)$ \\
Smoke exposure in home & 1.09 & 1.62 & 1.28 \\
$0-7$ h/wk (vs $>7)$ & $(0.78,1.53)$ & $(1.09,2.40)$ & $(0.99,1.65)$ \\
Portion smoked & 0.90 & 2.37 & 1.32 \\
nearly all (vs not all) & $(0.60,1.35)$ & $(1.38,4.05)$ & $(0.96,1.82)$ \\
First cigarette within & 0.59 & 0.97 & 0.71 \\
30 min of waking & $(0.42,0.84)$ & $(0.61,1.54)$ & $(0.54,0.94)$ \\
$\quad$ vs later) & 1.48 & 1.21 & 1.30 \\
Cigarettes/day & $(0.97,2.23)$ & $(0.76,1.93)$ & $(0.97,1.76)$ \\
$<20$ (vs $\geqslant 20)$ & 1.37 & 1.26 & 1.32 \\
Years smoked & $(0.98,1.91)$ & $(0.84,1.88)$ & $(1.02,1.70)$ \\
$<10$ (vs $\geqslant 10)$ & & &
\end{tabular}

${ }^{a}$ Sample sizes for attempted/did not attempt. These sample sizes are smaller than in previous tables due to missing values for some variables.

previous tables due to missing values for some variables. interactions were observed for education $(\mathrm{p}=0.01)$, smoke exposure in home $(\mathrm{p}=0.14)$, portion smoked $(p=0.005)$, and time after waking of the first cigarette $(p=0.10)$. In addition, two interactions with education were observed, portions smoked $(p=0.04)$ and cigarettes/day $(\mathrm{p}=0.11)$.

Odds ratios are adjusted for all variables in the logistic model. Age, age at initiation of smoking, and most friends are smokers were dropped from the final models.

Table 5 Adjusted odds ratios (95\% confidence limits) for various predictors of success at quitting smoking by educational level

\begin{tabular}{lccc}
\hline & \multicolumn{3}{c}{ Educational level } \\
\cline { 2 - 4 } & $<12$ years & $\geqslant 12$ years & All \\
\hline (n/n) & $(56 / 243)$ & $(85 / 232)$ & $(141 / 475)$ \\
Race & 1.83 & 1.69 & 1.83 \\
white (vs black) & $(0.89,3.78)$ & $(0.94,3.02)$ & $(1.17,2.87)$ \\
Education & - & - & 10.17 \\
$\geqslant 12$ yrs (vs < 12) & 2.06 & 0.91 & $1.80)$ \\
Sex & $(1.09,3.88)$ & $(0.52,1.59)$ & $(0.89,2.02)$ \\
female (vs male) & 1.62 & 0.91 & 1.13 \\
Annual family income & $(0.83,3.17)$ & $(0.50,1.65)$ & $(0.73,1.76)$ \\
$\geqslant \$ 25000$ (vs < $\$ 25000)$ & 0.94 & 1.34 & 1.16 \\
Method & $(0.34,2.61)$ & $(0.62,2.88)$ & $(0.64,2.10)$ \\
assisted (vs unassisted) & 1.60 & 1.47 & 1.52 \\
Smoke exposure in home & $(0.87,2.97)$ & $(0.83,2.59)$ & $(1.01,2.29)$ \\
$0-7$ h/wk (vs $>7)$ & 2.73 & 2.15 & 2.33 \\
Portion smoked & $(1.40,5.34)$ & $(1.16,3.98)$ & $(1.49,3.64)$ \\
nearly all (vs not all) & 1.38 & 0.54 & 0.87 \\
First cigarette within & $(0.70,2.70)$ & $(0.27,1.07)$ & $(0.55,1.39)$ \\
30 min of waking & & & \\
(vs later) & 1.84 & 1.85 & 1.86 \\
Cigarettes/day & $(0.82,4.13)$ & $(0.91,3.76)$ & $(1.10,3.13)$ \\
$<20$ (vs $\geqslant 20)$ & 1.34 & 1.72 & 1.50 \\
Years smoked & $(0.71,2.51)$ & $(0.99,2.98)$ & $(1.00,2.25)$ \\
$<10$ (vs $\geqslant 10)$ & & &
\end{tabular}

a Sample sizes for succeeded/relapsed. These sample sizes are smaller than in previous tables due to missing values for some variables.

Note: Models presented by education due to multiple education interactions. Education interactions were observed for sex $(p=0.06)$, income $(p=0.18)$, and the time after waking of the first cigarette $(\mathrm{p}=0.06)$. No race interactions were observed.

Odds ratios are adjusted for all variables in the logistic model. Age, age at initiation of smoking, and most friends are smokers were dropped from the final models.
UNIVARIATE ASSOCIATIONS

Trends in the characteristics hypothesised to be predictive of attempt and success at stopping smoking were observed across the three categories of subjects (those who succeeded, relapsed, and never attempted to stop smoking; table 2). For example, education was highest in those who succeeded, intermediate in those who relapsed, and lowest in those who did not attempt to stop. Compared to those who relapsed and those who never tried to stop, those who succeeded had higher family incomes, smoked for fewer years, smoked fewer cigarettes per day, were less likely to have friends who were smokers, and were less likely to smoke within 30 minutes of waking. These findings were observed among blacks and whites. Among whites, age at initiation of smoking, the number of hours per week exposed to smoke in the home, and the portion of the cigarette that is smoked, were also univariate predictors.

\section{MULTIVARIATE PREDICTORS}

Multivariate predictors of an attempt to stop smoking among blacks and whites included a higher family income, and smoking for less than ten years (table 4). Higher education, minimal exposure to smoke in the home, and smoking nearly all of the cigarette were predictive of an attempt to stop smoking only among whites. The time of the day the first cigarette is smoked predicted attempt only among blacks.

Multivariate predictors of success included white race, minimal exposure to smoke in the home, smoking nearly all of the cigarette, and smoking fewer cigarettes per day (table 5). These associations were similar in the lesser and better educated. Among the lesser educated, women were significantly more likely to be successful.

\section{METHODS AND MOTIVATIONS}

The most frequently reported methods of stopping or of trying to stop were unassisted methods: stopping cold turkey, reported by $83 \%$, and cutting down or switching brands, reported by $41 \%$ (figure 2 ). Other unassisted methods reported with lesser frequency included substituting gum or candy for cigarettes $(3 \%)$, or using a non-prescription product $(2 \%)$. (These methods are included in the "other" category of figure 2.) Assisted methods were reported less frequently; overall, $10 \%$ reported going to a doctor or professional agency for help. Assisted methods included in the "other" category were nicotine gum $(4 \%)$ and hypnosis $(2 \%)$. Assisted methods were more frequently reported by whites than blacks $(20 \%$ vs $6 \%)$. Neither the type of method (assisted or unassisted) nor the specific method was predictive of success, in the overall sample, by race, or by education (not shown).

The most frequently reported motivation for attempting to stop smoking was a concern for the individual's own health (figure 3). A consistent education trend suggests that less 


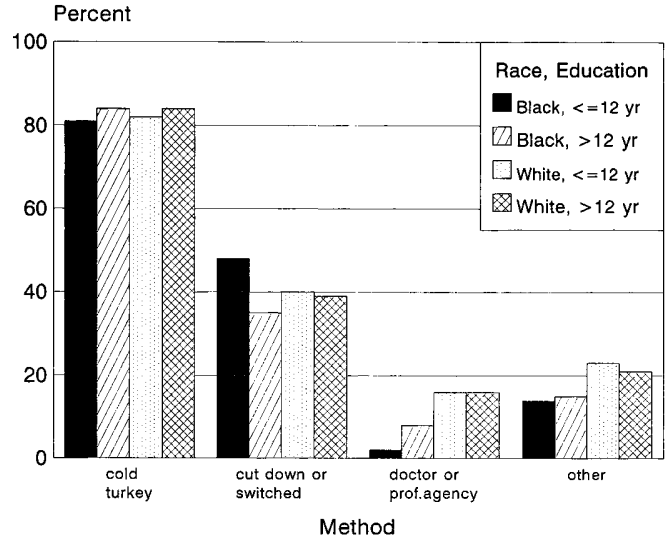

Figure 2 Reported methods used in stopping or trying to stop smoking in CARDIA subjects by race and education. Multiple responses were allowed. The most frequent responses in the "other" category included: substituting gum or candy for cigarettes, using a nonprescription product, using nicotine gum (a prescription product), and hypnosis. No other responses were reported by at least $2 \%$ of the sample.

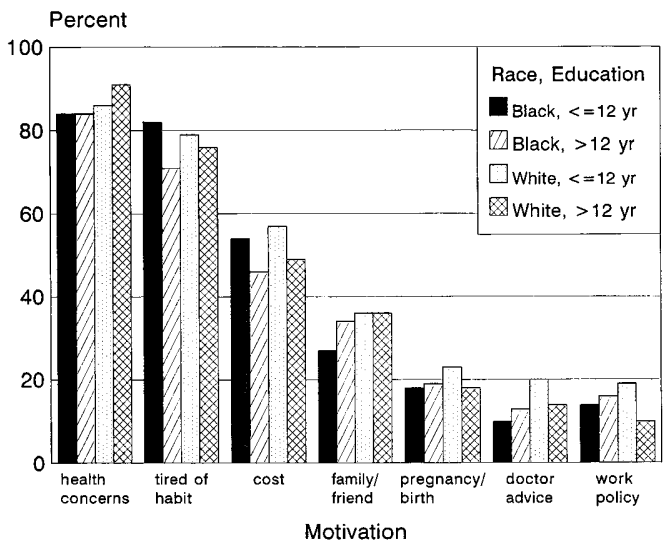

Figure 3 Reported motivations for stopping or trying to stop smoking in CARDIA subjects, by race and education. Workplace policy on smoking was only considered as a possible motivation in subjects who reported working indoors around others $(65 \%$ of the sample).

well educated individuals are more frequently motivated by cost and being tired of smoking. Fewer blacks than whites reported a family member or friend as motivation. Motivations did not differ between those who succeeded and those who relapsed, in the overall sample, by race, or by education (not shown).

\section{Discussion}

There are several limitations to this study. First, our definition of success differs from the currently accepted criteria. Twelve months of continuous abstinence has been suggested as a criterion for classifying an individual as a confirmed former smoker, given the dynamic nature of the cessation process. ${ }^{16}$ Such a criterion was not feasible in this study since we were examining a short time period. Consequently, some misclassification has undoubtedly occurred.

A further weakness is the likely overestimation of success rates. This may have resulted from (1) the above mentioned mis- classification; (2) an under-representation of smokers in the original cohort; or (3) the lack of complete follow-up among the cohort. With regard to the latter, since follow-up was poorer among smokers, it was probably also poorer in those who were unsuccessful in their attempts to stop or who did not attempt to stop during this period. Use of the baseline data would have partially alleviated this problem; however, we were unable to make this comparison since the 1990/91 questions concerning attempts to stop smoking did not inquire as far back as this exam.

Another limitation of this study is the use of three variables collected in 1990/91 as predictors of an event which occurred prior to that date. Two of these variables, the portion of the cigarette smoked and the time of the day the first cigarette is smoked, could have been modified by the quit attempt or affected by recall bias, and associations with these variables should be interpreted cautiously. The third variable, annual income, is less likely to be influenced by the quit attempt.

Attempts to stop smoking and success at stopping smoking were examined separately in this sample of young adults in an effort to identify reasons for the lower cessation rate in blacks compared to whites and in the less well educated versus the better educated. The lower cessation rate observed among blacks appears to be due primarily to less success at stopping smoking, and to a lesser extent, to fewer attempts being made to stop smoking. The poorer success rate observed among blacks compared to whites is consistent with the findings of others, ${ }^{9,10,12,13,17,18}$ but the slightly lower attempt rate in blacks is not consistent; others have primarily shown higher attempt rates in blacks. In the 1987 NHIS data, 38\% of blacks versus $31 \%$ of whites stopped smoking for at least one day in the previous year. ${ }^{1}$ Comparable figures in California in 1990 were $58 \%$ and $47 \%,{ }^{17}$ and in the COMMIT study, $43 \%$ and $36 \%{ }^{19}$ Our more rigid definition of attempt (two or more days of abstinence), or the narrow, younger age range of this cohort, may explain this disparity.

White race persisted as an independent predictor of success after adjusting for numerous correlates. None of the factors studied, many of which differed significantly between races, accounted for the poorer success rate observed in blacks. Other factors which were not examined or were not measured validly may help explain the finding. For example, the role of social support ${ }^{14,20}$ may have been inadequately represented in the multivariate models. Indeed, important differences in social support were observed: black smokers more often reported having friends who were smokers and were less likely to report family or friends as a motivation for quitting. Another study has reported that blacks, compared to whites, report significantly less pressure from people to stop smoking, and are less likely to encourage others to do so. ${ }^{19}$ Other social/ cultural influences which may explain poorer success in minorities include: cigarette advertising directed at minorities, ${ }^{21}$ greater over- 
all life stress, ${ }^{20,22}$ limited access to health care, ${ }^{23}$ and less physician counselling on preventive behaviours including smoking cessation. ${ }^{24}$

Factors which might explain the poorer cessation rates in the less well educated were also examined. In the univariate associations, the less well educated were less likely to attempt to stop smoking and were less successful than the better educated. However, these associations were diminished in the multivariate model when highly correlated variables such as race and income were included. Only among white subjects was better education associated with attempt to stop smoking. No association was found with success. The association with attempt and not with success is intriguing. This may be related to the greater exposure to anti-smoking materials among the better educated rather than to differences in behaviour-changing skills. ${ }^{25}$

Family income was a significant correlate of an attempt to stop smoking, among black and white smokers although, interestingly, income did not correlate with success (although it did in another study ${ }^{9}$ ). In this study, a significant interaction between income and education suggests that among the less well educated, income is a stronger correlate of success.

Gender differences in attempt and success rates were not a prominent finding, which is consistent with other reports. ${ }^{5,9,10}$ However, among the less well educated, women were more likely to succeed than men.

Friends and family members who smoke were also predictors of outcome in this study. Those exposed to minimal amounts of smoke in the home were more successful in their attempts to stop smoking and, among whites, were more likely to attempt to stop smoking. Supportive relationships have been previously shown to play an important role in the control of tobacco use. ${ }^{26,27}$ Such findings strengthen the case for the development of smoking cessation programmes targeted at entire households.

Numerous other characteristics of smoking were also examined. As observed previously, ${ }^{6,8,9,16}$ smoking fewer cigarettes per day was predictive of success. Also, those who had smoked for fewer years were more likely to attempt to stop. An unexpected finding was that persons who smoked less than all of the cigarette were less likely to attempt to stop (whites only) and more likely to relapse. One explanation may be that these individuals perceived that cutting back in this way was a sufficient change in behaviour. Finally, nicotine dependence, defined as smoking the first cigarette within 30 minutes of waking, was associated with a reduced rate of attempt among blacks only. Others have shown this index as an independent predictor of relapse. ${ }^{13}$ Nicotine dependence was more prevalent in blacks, despite their smoking fewer cigarettes per day, a finding which has been shown by others. ${ }^{19}$ Possible explanations include the preference for high-nicotine, mentholated brands among blacks $^{28}$ and racial differences in the metabolism of nicotine. ${ }^{29}$
This is one of the first reports to show the extent to which the races and education groups differ in their utilisation of certain cessation methods and the motivations reported for stopping or trying to stop smoking. While both races reported high rates of unassisted methods such as "cold turkey" and cutting down or switching brands (shown previously ${ }^{30}$ ), whites were twice as likely to report using an assisted method regardless of education. The primary assisted method reported by these young adults was a doctor or other professional. Others have reported a smaller racial difference ${ }^{9}$ and similarly low rates of assisted attempts among blacks. ${ }^{11}$ Education differences were less striking, although less well educated subjects tended to report being motivated more by the expense and annoyance with smoking than the better educated. Although two reports have observed better success rates among those who tried to stop on their own, ${ }^{8,10}$ the type of cessation method did not predict success in this study.

Several aspects of this study give further credence to the findings. First, this is a cohort in which smoking cessation occurred naturally without the suggestion of intervention. In addition, the results were obtained from data collected in a prospective manner, using crosssectional surveys, rather than in a retrospective manner as in many of the previous studies. Only one other prospective study of a freeliving population has been published. ${ }^{9}$ Finally, the CARDIA cohort included sufficient numbers of blacks and whites of various educational backgrounds for subgroup analyses. Consequently, numerous biases which were present in other reports are avoided in this study.

In order to achieve the US tobacco control objective for the year 2000 to reduce cigarette smoking prevalence to no more than $15 \%,{ }^{31}$ it is essential that millions of Americans stop smoking, an undertaking which is met with limited success by several segments of society. In particular, black Americans have less success at stopping smoking than whites. The factors examined here did not explain this racial disparity. Programmes focused on identifying the underlying predictors and implementing strategies to address them should be a high priority.

This paper was presented at the 64th Scientific Sessions of the American Heart Association, Anaheim, California, USA in November 1991 .

Supper 1991. NHI BI contracts N01-HC-48047, N01-HC 48048, N01-HC-48049, N01-HC-48050 and N01-HC-95095.

1 US Department of Health and Human Services. The health benefits of smoking cessation. Washington, DC: DHHS, benefits of smoking cessation. Washington, DC:

2 Wagenknecht LE, Perkins LL, Cutter GR, Sidney S, Burke GL, Manolio TA, et al. Cigarette smoking behavior is strongly related to educational status: the CARDIA study. Prev Med 1990; 19: 158-69.

3 Fiore MC, Novotny TE, Pierce JP, Hatziandreu EJ, Pate $\mathrm{KM}$, Davis RM. Trends in cigarette smoking in the United States: the changing influence of gender and race. f $A M A 1989 ; 261$ : 49-55.

4 Pierce JP, Fiore MC, Novotny TE, Hatziandreu EJ, Davis RM. Trends in cigarette smoking in the United States. Educational differences are increasing. $\mathcal{F} A M A 1989 ; 261$ $56-60$

5 Freund KM, D'Agostino RB, Belanger AJ, Kannel WB, Stokes J. Predictors of smoking cessation: the Framingham study. Am $\mathcal{F}$ Epidemiol 1992; 135: 957-64. 
6 Coambs RB, Li S, Kozlowski LT. Age interacts with heaviness of smoking in predicting success in cessation of smoking. Am F Epidemiol 1992; 135: 240-6.

7 Hymowitz N, Sexton M, Ockene J, Grandits G. Baseline factors associated with smoking cessation and relapse. Prev Med 1991; 20:590-601.

8 Hellman R, Cummings KM, Haughey BP, Zielezny MA, O'Shea RMO. Predictors of attempting and succeeding at O'Shea RMO. Predictors of attempting and succeeding

9 McWhorter WP, Boyd GM, Mattson ME. Predictors of quitting smoking: the NHANES I follow-up experience. f Clin Epidemiol 1990; 43: 1399-405.

10 Fiore MC, Novotny TE, Pierce JP, Giovino GA, Hatziandreu EJ, Newcomb PA, et al. Methods used to quit smoking in the United States. Do cessation programs help? f $A M A$ 1990; 263: 2760-5.

11 Orleans CT, Schoenback VJ, Salmon MA, Strecher VJ, Kalsbeek W, Quade D, et al. A survey of smoking and quitting patterns among black Americans. Am f Public Health 1989; 79: 176-81.

12 Novotny TE, Warner KE, Kendrick JS, Remington PL. Smoking by blacks and whites: Socioeconomic and demographic differences. Am $\mathcal{F}$ Public Health 1988; 78: demograph

13 Kabat GC, Wyder EL. Determinants of quitting smoking. Am F Public Health 1987; 77 : 1301-5.

14 Mermelstein R, Cohen S, Lichtenstein E, Baer JS, Kamarck $\mathrm{T}$. Social support and smoking cessation and maintenance. I Consult Clin Psychol 1986; 54: 447-53.

15 Friedman GD, Cutter GR, Donahue RP, Hughes GH, Hulley SB, Jacobs DR, et al. CARDIA: study design, recruitment, and some characteristics of the examined subjects. F Clin Epidemiol 1988; 41 : 1105-16.

16 Cohen S, Lichtenstein E, Prochaska JO, Rossi JS, Gritz $\mathrm{ER}$, Carr CR, et al. Debunking myths about self-quitting. Evidence from 10 prospective studies of persons who attempt to quit smoking by themselves. Am Psychol 1989; 44: 1355-65.

17 Burns D, Pierce JP. Tobacco use in California 1990-1991. Sacramento: California Department of Health Services,

18 Moss AJ. Changes in cigarette smoking and current smoking practices among adults: United States, 1978. Advance Data 1979; 52: 1-15.

19 Royce JM, Hymowitz N, Corbett K, Hartwell TD, Orlandi
MA. Smoking cessation factors among African Americans and whites. Am f Public Health 1993; 83: 220-6.

20 Romano PS, Bloom J, Syme SL. Smoking, social support and hassles in an urban African-American community. Am $\mathcal{F}$ Public Health 1991; 81: 1415-22.

21 Cummings KM, Giovino G, Mendicino AJ. Cigarette advertising and black-white differences in brand preference. Public Health Rep 1987; 102: 698-701.

22 Pechacek TF, Danaher BG. How and why people quit smoking: a cognitive-behavioral analysis. In: Kendal PC, Hollon SD, eds, Cognitive-behavioral interventions: theory research and procedures. New York: Academic Press, 1979: 389-422.

23 Blendon RJ, Aiken LH, Freeman HE, Corey CR. Access to medical care for black and white Americans. $\mathcal{F} A M A$ $1989 ; 261: 278-81$.

24 Gemson DH, Elinson J, Messeri P. Differences in physician prevention practice patterns for white and minority patients. 7 Community Health 1988 ; 13: 53-64.

25 Macaskill P, Pierce JP, Simpson JM, Lyle DM. Mass medial-led antismoking campaign can remove the education gap in quitting behavior. Am 7 Public Health 1992 82: $96-8$.

26 Coppotelli $\mathrm{H}$, Orleans CT. Partner support and other determinants of smoking cessation maintenance amon women. $\mathcal{F}$ Consult Clin Psychol 1985; 53: 455-60

27 Mermelstein R, Lichtenstein E, McIntyre K. Partne support and relapse in smoking cessation programs. $f$ Consult Clin Psychol 1983; 51: 465-6.

28 Orleans CT, Strecher VJ, Schoenback VJ, Salmon MA Blackmon C. Smoking cessation initiatives for black Americans: recommendations for research and intervention. Health Educ Res 1989 ; 4: 13-25.

29 Wagenknecht LE, Cutter GR, Haley NJ, Sidney S, Manolio TA, Hughes GH, et al. Racial differences in serum cotinine levels among smokers in the Coronary Artery Risk Development in (Young) Adults Study. Am f Public Health $1990 ; 80: 1053-6$.

30 Hahn LP, Folsom AR, Sprafka JM, Norsted SW. Cigarette smoking and cessation behaviors among urban blacks and whites. Public Health Rep 1990; 105: 290-5.

31 US Department of Health and Human Services. Healthy people 2000. Washington, DC: DHHS, 1991. (DHHS Publication No (PHS) 92-50212.)

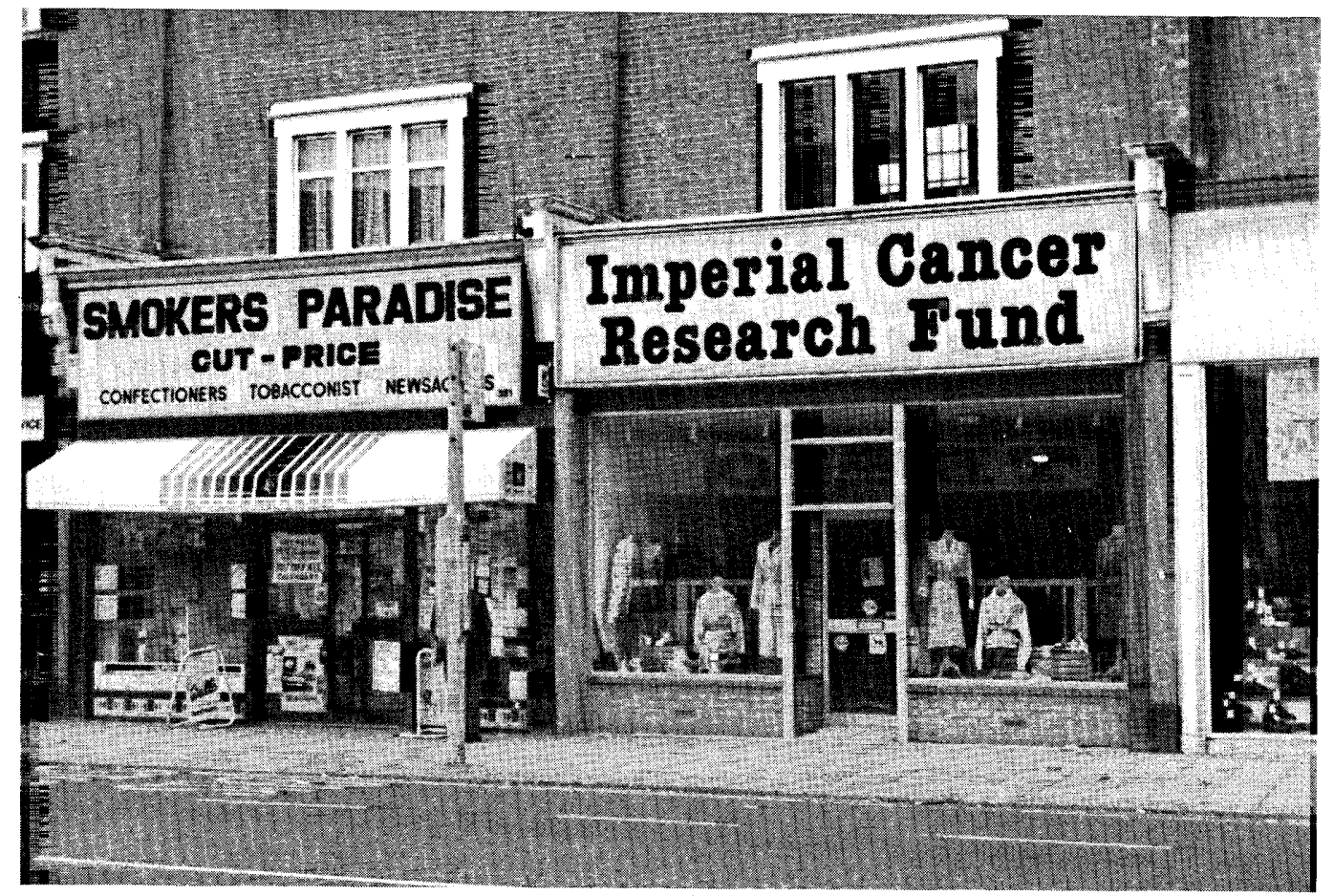

A London scene. Courtesy H. Murad.

\section{Imperial Cancer Research Fund}

